IOSR Journal of Engineering

e-ISSN: 2250-3021, p-ISSN: 2278-8719,

Vol. 2, Issue 12 (Dec. 2012) ||V2|| PP 28-33

\title{
Factors affect on Requirement Prioritization
}

\author{
Shams Ul Hassan, Salman Afsar Awan, Fahad Jaan, Hira Akmal \\ Agriculture University, Faisalabad, 38000, Pakistan,
}

\begin{abstract}
Software engineering research is yet in its early stages hence it needs evaluation. So, software engineers think about experimental research and try to adopt analytical approaches to validate results like in other sciences. It should be asserting that requirement engineering process is to use requirements prioritization. The use of requirements prioritization helps the anatomy of requirements and isolates the most important requirements. A lot of prioritization techniques, practices and methodologies are used in software requirements. But lack of empirical search program and proficient methodology, was not decide which should be implemented. In this research, the requirement prioritization for systematical reviews was carried out. Based on systematic review, a framework is introduced for further research within requirement prioritization. This paper described a framework for scrutinize the discussion that take place during requirements elicitation and requirements prioritization. The survey presented in the paper gives a practical view how to prioritize the requirements. It also reflects the requirements prioritization in the industries needs. Which factors of the requirements engineering affect the requirements prioritization.
\end{abstract}

Keywords : Framework, Requirements Prioritization, Software Engineering, Requirement engineering, Systematic Review

\section{INTRODUCTION}

The term requirement may be defined as demand or need. In the world of the software engineering, a requirement is a explanation of what the purposed system should do or perform. A system may have a lot of requirements. Software requirements demand what must be accomplished, shaped or provided. Requirement elicitation is all about knowing the desires of stakeholders. [1] The term requirement has been used in the software engineering society since 1960. The requirements provide a firm basis for the success of the project and delivery of the product. The requirements often shrink the gap between software team and end users. Requirement phase begin at the analysis phase. Requirements managed throughout the project life cycle. So requirements are the report of the services that a system must perform and operate under some constraints.

Requirement Engineering (RE) is worried about the naming of the goals, achieved by the imagine system. Most difficult and critical to be achieve the better quality of the requirement. Incomplete, inconsistent and ambiguous requirements have the most serious impact on the required software. If requirement errors correction perform late the cost raise up to 200 times as compared the requirement errors correction perform in time. Requirement Engineering deals with a wide range of business domains and tasks like decision, administrative support. [2]

Even though the considerable Requirement Engineering (RE) explore and research attempts over the many past years but the gap between the industry and research still hang about constantly. Now Requirement Engineering research society tries to address these issues. [3] Requirement Engineering (RE) comparatively new field. Requirement Engineering is a system and processes that covers the activities based on computer system. [4] Requirement elicitation and requirement management have healthy documented using UML (Unified Modeling Language). Many tools are available that support the UML standards in any way. These tools have their own advantages and disadvantages. Many available tools need customization to meet the special requirements. The prototypes also used to create system requirements automatically. [5]

Requirement elicitation is a technique to collect the requirements. Professionals like system engineers, software analysts work with the stakeholders; this is useful for finding and solving the problems. There are many requirement elicitation techniques like interviews; questionnaire etc. [6] Requirement elicitation is the main movement in the requirement engineering process. It occupied to find out the needs and collecting the required software requirements from the stakeholders. There are some problems occurred by software engineers when they perform requirement elicitation processes. Requirement elicitation faced many problems like users' involvement and perfect documentation. To get the correct requirements and complete requirements required the right stakeholders. So there must be need to adopt the technique that could help in recognize and decide the stakeholders. [7] 
It is the major problem with software developers that developed software does not meet stakeholders' requirements. It stresses the user to focus importance of the requirements concerning the implementation cost. Time pressure and budget constraint force the software engineers to make plan for consecutive releases of software. [8] Prioritization is a method where person or group of persons rank the item in order based on their recognize importance. Prioritization is the process of starting procedure based upon urgent and long-standing need of the organizations. Prioritization leads the organization sensible plan and performs on leaders dream for the future business plan. In any good organization, it is significant to develop priorities based on IT project to move right directions. Due to time constraint and lack of budget, it is very complicated to execute all requirements that elicited during the analysis. So prioritization helps to determine which would apply first.

The objective of the current article is to knowing the factors affect on the requirement prioritization. The current survey provides the support of requirement prioritization. These requirement prioritization factors (RPF) improve the ability of the prioritization. These requirement prioritization factors (RPF) effect the cost of the imagine system.

\section{REQUIREMENT PRIORITIZATION AND STAKEHOLDERS}

The role of prioritization of requirements is imperative to an efficient and result oriented product development. Requirement prioritization marks high risk and most important requirements to be given priority in implementation. [9] Usually stakeholder expectations are high but shortage of time, limited resources and budget constraints make it difficult to implement all requirements that have been elicited for the system. With the help of prioritization, it can be decide which one should be implement first.

In several known customers prioritization adopt difficult shapes because of different users involve as well as have different thinking and separate preferences. A most important issue arises when stakeholders are scattered different geographical areas. There priorities are not same, all the time. Every requirement analyst performs the process of prioritization. Software engineers are not well trained to elicit, gather, analyze and security requirements. [10] Requirement prioritization is extremely dangerous are of requirement engineering. Without appropriate requirement prioritization, offer by different stakeholders, the necessary objectives of the end product can not be achieved properly. The product may fails to meet its heart objectives on the basis of several requirements prioritization techniques presented by different researchers. [11]

\section{REQUIREMENT PRIORITIZATION AND AGILE SOFTWARE DEVELOPMENT}

Agile development techniques become more accepted during last decade. Many methods built for the faster delivery of the software and those techniques ensure the developed software meets the user requirements. Requirement engineering depends on the documentation for the customer needs and agile technique depends on face to face association between the stakeholders to get the same requirements.[12] Agile software development scenarios and stories are used. Use case modeling also popular method for requirements gathering and analysis. To collect the requirements through these methods always are complete, clear and validate. [13]

In habitual software development techniques customers or stakeholders predefined their software requirements and software analysts' analysis these requirements for specification. It is very difficult and not cost effective for complete requirements. This difficulty solves by the XP methods. [14] Agile methods give the importance of continuous requirements prioritization from customer point of view. A agile approach give the client's critical role in making decision. [15]

\section{RESEARCH METHOD AND DATA COLLECTION}

The experience was drawn from this study conducted on seventeen different industries. The purpose of the survey based research was to find out how the software engineers could produce the product that might give good satisfaction of the stakeholder needs by the requirement prioritization. The organizations have different type of application domain. Through the questionnaire survey, studied the actual requirements prioritization work in special stage of software development. To get the clarification of the current requirement prioritization methods in-depth interviews were conducted. There are three groups according to their application domain.

Table 1: Type of Application Domain

\begin{tabular}{|l|l|l|}
\hline Company & $\begin{array}{l}\text { Number of } \\
\text { Employees }\end{array}$ & $\begin{array}{l}\text { Application } \\
\text { Domain }\end{array}$ \\
\hline A & 35 & Processing \\
\hline B & 73 & $\begin{array}{l}\text { Non } \\
\text { Processing }\end{array}$ \\
\hline C & 2658 & IT professional \\
\hline
\end{tabular}




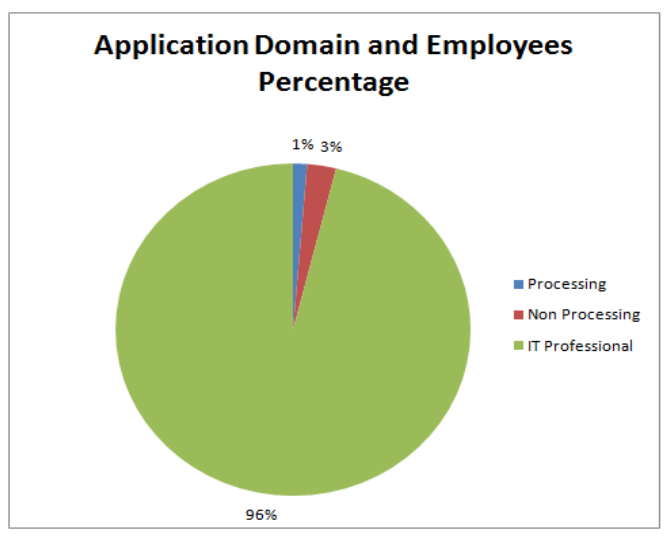

Figure 1:Domain Expert Employees

The purpose of the focus group was to determine how organizations prioritize the requirements and which development phases involved in practice. Through the survey, it was concluded that which issues effect the prioritization and from which basis the stakeholders elicit the information on which they decide the requirement prioritization. In addition, picture was drawn to minimize the cost and enhance the effectiveness of the software though the requirement prioritization. The stakeholders and their associations to the requirement prioritization have shown the following table.

Table 2 : Company and its stakeholder's designation

\begin{tabular}{|l|l|}
\hline Company & $\begin{array}{l}\text { Relation between stakeholders } \\
\text { and prioritization }\end{array}$ \\
\hline $\mathrm{A}$ & $\begin{array}{l}\text { Manager and Asst. Manager elicit } \\
\text { the requirement and prioritize the } \\
\text { requirements }\end{array}$ \\
\hline $\mathrm{B}$ & $\begin{array}{l}\text { Asst. Manager and software } \\
\text { engineer gather information and } \\
\text { write down the document about } \\
\text { requirement }\end{array}$ \\
\hline $\mathrm{C}$ & $\begin{array}{l}\text { Manager, Asst. Manager and } \\
\text { software engineers elicit the } \\
\text { requirements, prioritize } \\
\text { requirements and implement the } \\
\text { actual requirements }\end{array}$ \\
\hline
\end{tabular}

The age of the analysts affect the result of requirement prioritization as show below.

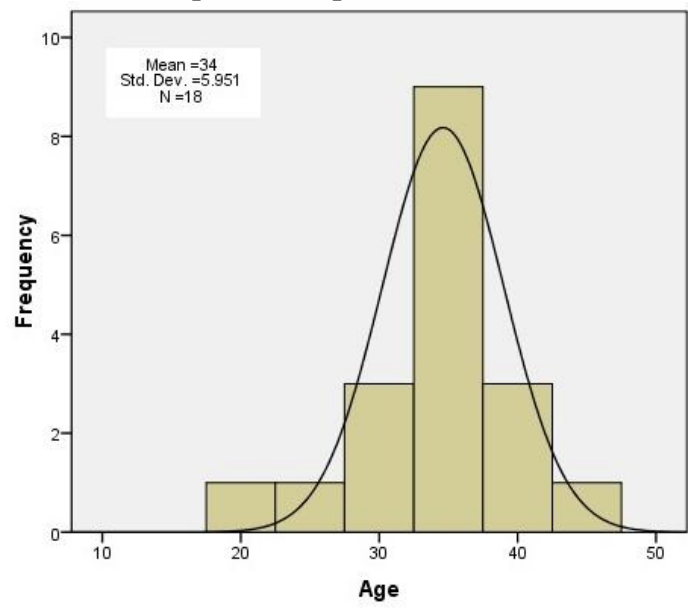

Figure 2: Frequency Distribution

The bell-shaped histogram shows the most frequency of age counts bunches in the middle and with the counts fading off out in the tails. It is a good model for the data. The histogram helps in making decisions in which age of people is a good analysis for requirements prioritization. The most measurements lies between the 
30 and 40 years age group people. The analysts who have the ages below 30 years or above 40 years did not show accurate results. Although below 30 years, analysts are so energetic and hard worker but have a little experience in the relevant field. Due to this reason they could not show cost effective results. Above 40 years analysts have so much experience but they loose their working power and activeness.

Graphical presentation of the leader experiences of the participants.

\section{Leader Experience (Years)}

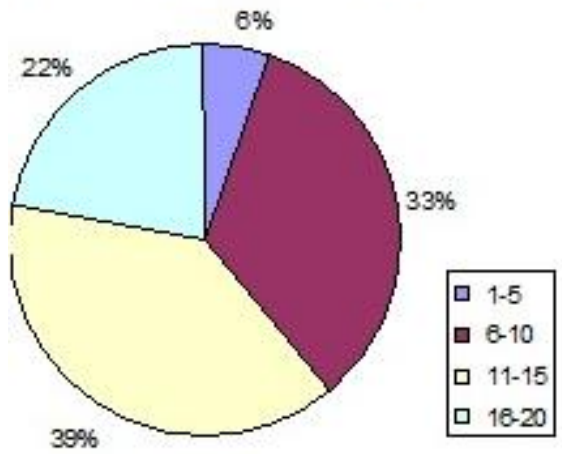

Figure 3: $\quad$ Leader Year Wise Experience

The leader experience plays a vital role in a good and effective software development. The leader directly attaches with customers and improves the prioritization of requirement. Leader considers the source to build the relationship to the customer. The relationship may be email, conference calls and face-to-face meeting. The leader should conduct effective meetings. Leader should plan the requirement session. He / She guides focal cause analysis and implement the requirements prioritization effort. The leader reviews the reports regularly to check the valid requirements. He / She make sure the requirements prioritization addressed by the customer according to the contract and balance with the stakeholder expectations. On the base of accurate requirements prioritization controls the future software direction. Leader experience with the remote customer and team is decidedly required. Leadership must have the both project management as well as people management experience. Leader must have knowledge that software architecture and development based on requirements prioritization. The leader should have the ability to face the elicitation and prioritize the requirements. He / She must have the capability to identify the requirements prioritization constraints.

Qualification of the analyst is also considered main thing in solving the requirements prioritization problems.

\section{Survey Participant Qualification}

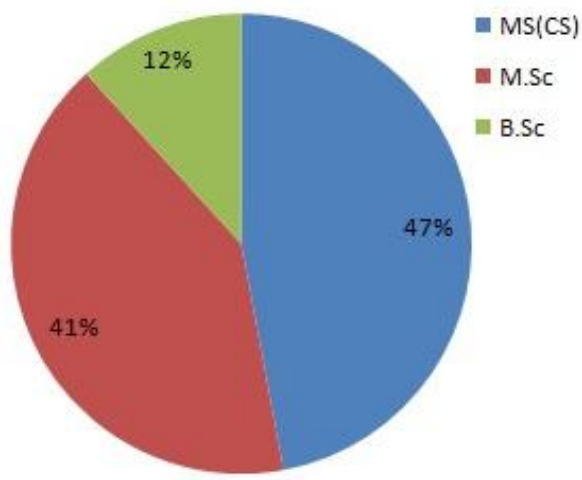

Figure 4: Participant qualification

The team leader or business analyst required at least bachelor's degree. A survey showed that the inhouse development industry try to hire at least bachelor employees for analysis, requirements analysis and prioritization but industries desired for business analysts having brilliant computer education like M.Sc. (CS) etc. Because their professional work involves solutions to meet the customer business needs and customer challenges. As industries have over all well educated and experienced persons in different working areas and industries businesses enhance day to day. In the result of this requirements of industries generate dynamically. To control and prioritized all those requirements, the team leader should be high qualified and have ability to translate industries requirements into system requirements with prioritization for software developers. They should have expertise in open range of business effect and software programs. Education generates the ability in analyst to understand the business requirements, identify those requirements, document those requirements and 
prioritized them for business application for software developers. They get the ability to cope the relationship between different departments, effective communication, strategy of development those prioritized requirements.

The importance of the requirements is never neglected. The requirements prioritization is based on the following factors.

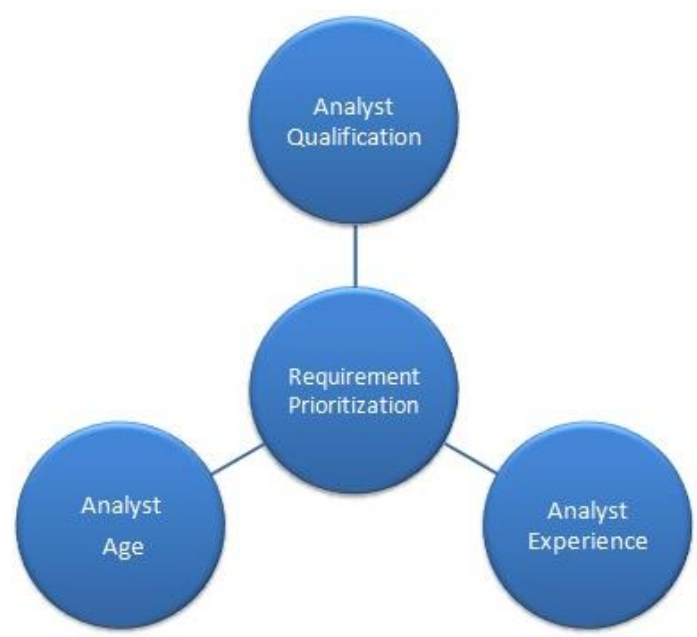

Figure 5: Purposed Frameworks

Study indicated that there are three factors which affect the priorities. It is the base line for the profit of any organization. These factors minimize the gap between the stakeholders. Any issue like relationships, communication problem and project involvement between the customers and analysts can be shrinking using these factors. There is no defined method for in-house development to prioritize the requirements. The organization must know these attributes in any software engineers. Any software developer who contains these attributes can make easily requirements prioritization and logical implementation of these requirements. The skill and education attributes cover the geographical region made their requirements priorities. It is not easy to say which individual factors affect the prioritization of the requirements.

\section{CONCLUSION}

The study has been conducted at three types of industries, to find out the results about requirements prioritization that gives the high level satisfaction of the customer. To achieve the explanation of the actual requirements prioritization, conduct the survey in-depth. The purpose of the survey was to determine how organizations prioritize the requirements. The term priority is the property or attribute of the requirement. In the survey organization, the requirements elicitation and requirements prioritization interacts the domain expert users.

The survey study indicated that there are three factors like analyst qualification, experience and age of the analyst, which affect the prioritization. These factors help to minimize the distance between the stakeholders. The defined three factors resolved the issues like relationships, communication problems between users and software engineers. Any software developer pursuing these attributes can make easily requirements prioritization and implementation of the requirements. Accurate requirements prioritization produced the cost effective solution for the organization.

\section{REFERENCES}

1). Sadiq .M and Mohd .S (2009), "Elicitation and Prioritization of Software Requirements". Internation Journal of Recent Trends in Engineering, Vol.2, No.3, pp. 138-142.

2). Lamsweerde, A.V (2000), Requirement Engineering in the Year 00: A Research Perspective. Proc. $22^{\text {nd }}$ Int. Conf. on the Software Engineering, University of Limerick, Ireland.

3). Sparrow .L., et. al. (2006), The Slow Wheel of Requirements Engineering Research: Responding to the Challenges of Societal Change. Deakin University, Australia.

4). Arif .S., et. Al. (2010), Requirements Engineering Processes Tools/Technology, \& Methodologies. Int. Journal of Reviews in Computing. Islamabad, Pakistan.

5). Meisenbacher .1.K. (2005), The Challenges of Tool Integration for requirements Engineering. Proc. Of SREO'05. France.

6). Ganesh and Gunda (2008), Requirement Engineering: Elicitation Techniques.Dept. of Technology, Mathematics and Computer Science. Sweden. 
7). Rozilawati .A and Fares .A (2011), Selecting he Right Stakeholders for Requirements Elicitation: A Systematic Approach. Journal of theortical and Applied Information Technology. Malaysia.Vol.33, No.2, pp.250-257.

8). Viggo .A (2005), An Experiment Comparision of Five Prioritization Methods Master Thesis Software Engineering, Sweden.

9). Joachim .K and Kevin .R (1997), A Cost-Value Approach for Prioritizing Requirements, IEEE Software, Germany.

10). Firesmith .D.G., (2003), Engineering Security Requirements. Journal of Object Technology. U.S.A. Vol.2, No.1, pp. 53-68.

11). Ramzan .M., et. al.(2011), Value Based Intelligent Requirements prioritization (VIRP): Expert Driven Fuzzy Logic Based Prioritization Technique. Int. Journal. Innovative Computing, Information and Control. Islamabad, Pakisatn. Vol.7, No.3, pp 1017-1038.

12). Paetsch .F., et. al. (2003), Requirement Engineering and Agile Software Development. Proc. $20^{\text {th }}$ IEEE Int. Workshop on Enabling technologies:Infrastructure for Collaborative Enterprises(WETICE’03). Washington, USA.

13). Firesmith .D (2004), Generating Complete. Unambiguous, and Verifiable Requirements from Stories, Scenarios and Use Cases. Journal of Object Technology. U.S.A. Vol.3, No.10, pp. 27-39.

14). Chetankumar .P and Muthu .R (2009), Story Card Based agile Software Development. Int. Journal of Hybride Information Technology. Vol.2, No.2, pp.125-140.

15). Reprioritization the Requirements in Agile Software Development: towards a conceptual model from clients perspective. Available at http://eprints.eemcs.utwente.nl/16055/01/SEKE-Racheva-Daneva.pdf 